\title{
Vibration in a Cracked Machine Tool Spindle with Magnetic Bearings
}

\author{
Huang-Kuang Kung and Bo-Wun Huang*
}

Department of Mechanical Engineering, Cheng Shiu University, Taiwan

\begin{abstract}
Due to manufacturing flaws or cyclic loading, cracks frequently appear in a rotating spindle system. These cracks markedly affect the dynamic characteristics in higher modes of the rotating machinery. For faster rotational speeds, especially for super-high-speed cutting, a spindle with magnetic bearings is necessary. However, most investigations into spindle system dynamic characteristics have been confined to ball-bearing-type spindles. The dynamic response of rotating cracked spindle systems with magnetic bearings is examined in this article. A Euler-Bernoulli beam of circular cross section is used to approximate the spindle and the Hamilton principle is employed to derive the equation of motion for the spindle system. The effects of crack depth, rotation speed and bearing length on the dynamic response of a rotating magnetic bearing spindle system are studied.
\end{abstract}

\section{INTRODUCTION}

Cracks frequently appear in rotating machinery due to manufacturing flaws or cyclic fatigue during operation. Numerous cracks can be observed after severe operating conditions, especially in high speed spindles $[1,2]$. Local structural irregularities caused by cracks in the spindle may significantly change the dynamic behavior of a rotating machinery system. The effects of cracks on the dynamic and static behaviors of structures have been studied by a number of researchers [3-5]. The effects of cracks on spindle dynamics, shaft and rotor systems, were also studied by researchers [6-9]. When a spindle rotates, the vibrational response is altered by the crack opening and closing in each cycle. Most investigations were motivated by the hypothesis that only opening cracks markedly change the spindle dynamics. This paper focuses on the dynamics of a spindle with a transverse crack.

High speed machining is one of the most modern manufacturing engineering technologies. In a machining system, the spindle is the most critical element that affects the dynamic performance and capabilities of the system in the machining process. However focusing exclusively on the spindle system is insufficient because the bearings can change the dynamics of a machining spindle system. Hence, the bearing effects on the spindle system must also be considered. Bearings are used in many rotating machines to brace the rotating spindles and rotors. In the past, the required rotor speed was low, allowing ball and roller bearings to be used in rotating machinery. High temperatures are generated with ball-bearing spindle systems operating at high speeds. The high temperatures often bring about machine failure. To attain greater complexity and accuracy, modern engineering technologies demand machinery that can be run at high speeds. To avoid the high temperatures generated by the contact between the spindles and bearings, non-contact magnetic bearings are

*Address correspondence to this author at the Department of Mechanical Engineering, Cheng Shiu University, Taiwan;

E-mail: huangbw@csu.edu.tw used for the spindle and rotor in high speed rotating machinery.

Traditionally, ball bearings have been used to support the spindle systems when the rotational speed was not high. Previous investigations on bearing spindle systems were confined to spindles with ball bearings. In some studies, the focus was on the dynamic response of a spindle supported by bearings $[10,11]$. At higher speeds, this bearing changes the stiffness of the entire spindle system and significantly alters the system properties [12-15]. Precise machining requires higher spindle speeds, making the magnetic-bearing spindle necessary. Investigations as [16-20] studied the performance and dynamic properties of magnetic bearings. Most studies deal with a magnetic ring for a radial magnetic bearing used as an unlimited one long magnetic bar for a permanent magnetic bearing. Investigation as [21] studied the bearing capacity and stiffness of radial magnetic bearings.

Thus far, most investigations as [22-24] on the dynamic characteristics of a cracked spindle system were limited to ball-bearing-type spindles. This study examines the crack effects on the dynamic response of a rotating spindle system with magnetic bearings. A Euler-Bernoulli beam of circular cross section was used to approximate the spindle model. The equations of motion for the bearing-spindle system were derived using the Galerkin method and Hamilton principle. A model the size of an actual spindle system was used. To simplify the calculations, massless springs were employed to model the stiffness of the magnetic bearings. The effects of crack depth, rotational speed and bearing length on the dynamic response of a spindle system were investigated.

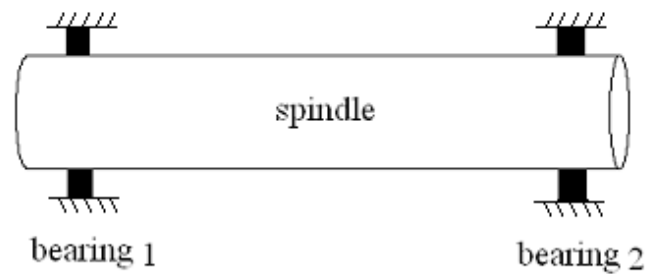

a spindle supported by bearings 

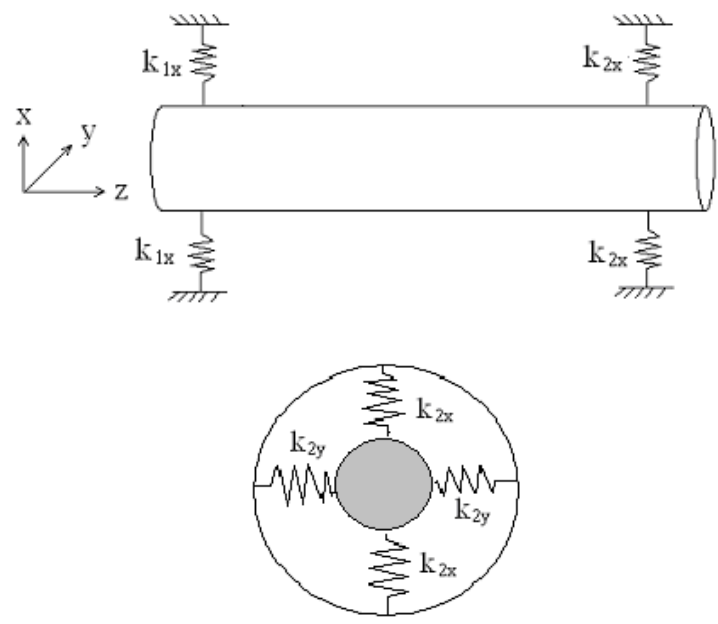

a simple model of bearing spindle system

Fig. (1). A rotating spindle with bearings scheme.

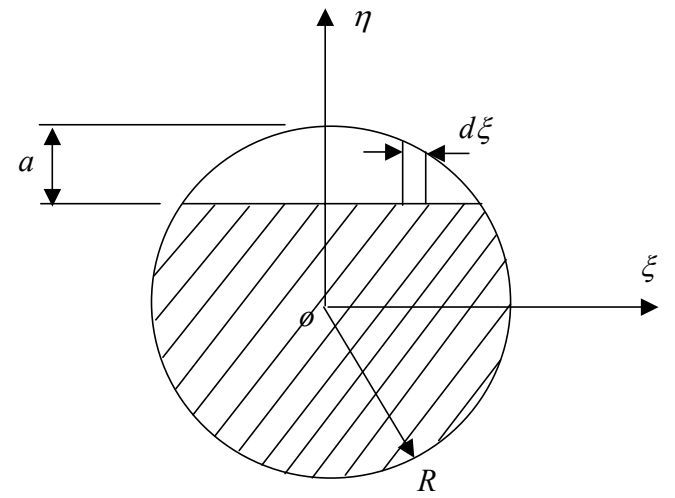

Fig. (2). Geometry of a cracked spindle.

\section{Theory}

This paper considers a spindle supported by magnetic bearings, as shown in Fig. (1a), to elucidate the dynamic response of a spindle system. Fig. (1b) presents a simple model for this bearing-spindle system. In this model, massless springs are employed to simulate the stiffness of the magnetic bearing and support the spindle. The rotational speed $\Omega$ of the spindle cannot be ignored in the rotating machinery bearing application. In this study, the deflection components $v(z, t)$, and $u(z, t)$ denote the two transverse flexible deflections of the spindle system. $E$ and $I$ represent the Young's Modulus and area inertia of the spindle, respectively. Only the transverse flexible deflections are studied in this article.

According to [25], the governing equations of the spindle system are displayed as:

$$
\begin{aligned}
& \rho A \ddot{u}-2 \rho A \Omega \dot{v}-\rho A \Omega^{2} u+E I\left(u^{\prime \prime}\right)^{\prime \prime} \\
&+k_{x 1} u \delta\left(z-z_{1}\right)+k_{x 2} u \delta\left(z-z_{2}\right)=0 \\
& \rho A \ddot{v}+2 \rho A \Omega \dot{u}-\rho A \Omega^{2} v+E I\left(v^{\prime \prime}\right)^{\prime \prime} \\
& \quad+k_{y 1} v \delta\left(z-z_{1}\right)+k_{y 2} v \delta\left(z-z_{2}\right)=0
\end{aligned}
$$

where $k_{x 1}$ : the bearing stiffness in $u$ deflection at a position $z_{1}$,

$k_{y 1}$ : the bearing stiffness in $v$ deflection at a position $z_{1}$,

$k_{x 2}$ : the bearing stiffness in $u$ deflection at a position $z_{2}$,

$k_{y 2}$ : the bearing stiffness in $v$ deflection at a position $z_{2}$,

$\rho:$ density,

$A$ : cross section area,

$\Omega$ : rotating speed,

$\delta()$ : Dirac delta fuction,

$z_{1}$ : the first located position of bearings,

$z_{2}$ : the second located position of bearings.

For convenience, the dimensionless equations of motion for this spindle are:

$$
\begin{gathered}
\ddot{\bar{u}}-2 \sqrt{\frac{E I}{\rho A L^{4}}} \bar{\Omega} \dot{\bar{v}}+\frac{E I}{\rho A L^{4}}\left\{-\bar{\Omega}^{2} \bar{u}+\left(\bar{u}^{\prime \prime}\right)^{\prime \prime}\right. \\
\left.+\bar{k}_{x 1} \bar{u} \delta\left(\bar{z}-\bar{z}_{1}\right)+\bar{k}_{x 2} \bar{u} \delta\left(\bar{z}-\bar{z}_{2}\right)\right\}=0 \\
\ddot{\bar{v}}+2 \sqrt{\frac{E I}{\rho A L^{4}}} \bar{\Omega} \dot{\bar{u}}+\frac{E I}{\rho A L^{4}}\left\{-\bar{\Omega}^{2} \bar{v}+\left(\bar{v}^{\prime \prime}\right)^{\prime \prime}\right. \\
\left.+\bar{k}_{y 1} \bar{v} \delta\left(\bar{z}-\bar{z}_{1}\right)+\bar{k}_{y 2} \bar{v} \delta\left(\bar{z}-\bar{z}_{2}\right)\right\}=0
\end{gathered}
$$

where the dimensionless parameters are given using:

$$
\begin{aligned}
& \bar{z}=\frac{z}{L}, \bar{z}_{1}=\frac{z_{1}}{L}, \bar{z}_{2}=\frac{z_{2}}{L}, \bar{\Omega}=\Omega / \sqrt{\frac{E I}{\rho A L^{4}}}, \\
& \bar{u}(\bar{z})=\frac{u(\bar{z})}{L}, \bar{v}(\bar{z})=\frac{v(\bar{z})}{L}, \bar{k}_{x 1}=\frac{k_{x 1} L^{3}}{E I}, \\
& \bar{k}_{x 2}=\frac{k_{x 2} L^{3}}{E I}, \bar{k}_{y 1}=\frac{k_{y 1} L^{3}}{E I}, \bar{k}_{y 2}=\frac{k_{y 2} L^{3}}{E I}
\end{aligned}
$$

and the boundary conditions are:

$\bar{u}^{\prime \prime}=\bar{u}^{\prime \prime \prime}=\bar{v}^{\prime \prime}=\bar{v}^{\prime \prime \prime}=0$, at $\bar{z}=0$

$\bar{u}^{\prime \prime}=\bar{u}^{\prime \prime \prime}=\bar{v}^{\prime \prime}=\bar{v}^{\prime \prime \prime}=0$, at $\bar{z}=1$

The Galerkin method is employed to derive the spindle equations of motion in matrix form. Therefore, the solutions for Eqs. (3) and (4) can be assumed to be:

$$
\begin{aligned}
& \bar{u}(\bar{z}, t)=\sum_{i=1}^{m} \phi_{i}(\bar{z}) p_{i}(t) \\
& \bar{v}(\bar{z}, t)=\sum_{i=1}^{m} \varphi_{i}(\bar{z}) q_{i}(t)
\end{aligned}
$$

where $\varphi_{i}(\bar{z}), \phi_{i}(\bar{z})$ are comparison functions for the spindle system, and $p_{i}(t), q_{i}(t)$ are the time coefficients to be determined for the system. The exact solution for a beam with free-free boundary conditions is considered, and five comparison function modes are used.

$\phi_{i}(\bar{z})=\varphi_{i}(\bar{z})=\left(\lambda_{i} \bar{z}\right)^{2}\left(1-\cosh \lambda_{i} \bar{z} \cos \lambda_{i} \bar{z}\right)$ 
$\lambda_{i}=\left(i-\frac{3}{2}\right) \pi u^{*}(i-2), i=1,2,3, \cdots$

where $u^{*}()$ is the unit step function. Substituting Eqs. (10) and (11) into Eqs. (3) and (4) respectively, the equations of motion in matrix form for the spindle system can be derived as:

$\left[\begin{array}{cc}{[M]_{1}} & 0 \\ 0 & {[M]_{2}}\end{array}\right]\left\{\begin{array}{l}\ddot{p}(t) \\ \ddot{q}(t)\end{array}\right\}+2 \bar{\Omega} \gamma\left[\begin{array}{cc}0 & {[G]_{l}} \\ {[G]_{2}} & 0\end{array}\right]\left\{\begin{array}{l}\dot{p}(t) \\ \dot{q}(t)\end{array}\right\}$

$+\gamma^{2}\left[\begin{array}{cc}{\left[K_{e}\right]_{1}} & 0 \\ 0 & {\left[K_{e}\right]_{2}}\end{array}\right]\left\{\begin{array}{l}p(t) \\ q(t)\end{array}\right\}+\bar{\Omega}^{2} \gamma^{2}\left[\begin{array}{cc}{\left[K_{\Omega}\right]_{1}} & 0 \\ 0 & {\left[K_{\Omega}\right]_{2}}\end{array}\right]\left\{\begin{array}{l}p(t) \\ q(t)\end{array}\right\}$

$+\gamma^{2}\left[\begin{array}{cc}{\left[K_{s 1}\right]_{1}} & 0 \\ 0 & {\left[K_{s 1}\right]_{2}}\end{array}\right]\left\{\begin{array}{l}p(t) \\ q(t)\end{array}\right\}+\gamma^{2}\left[\begin{array}{cc}{\left[K_{s 2}\right]_{1}} & 0 \\ 0 & {\left[K_{s 2}\right]_{2}}\end{array}\right]\left\{\begin{array}{l}p(t) \\ q(t)\end{array}\right\}=0$

where $\gamma=\sqrt{\frac{E I}{\rho A L^{4}}}$.

The elements of the matrices in the above equation are given as follows,

$$
\begin{aligned}
& \left(m_{i j}\right)_{1}=\int_{0}^{1} \phi_{i} \phi_{j} d \bar{z}=-\left[\left(k_{\Omega}\right)_{i j}\right]_{1} \\
& \left(m_{i j}\right)_{2}=\int_{0}^{1} \varphi_{i} \varphi_{j} d \bar{z}=-\left[\left(k_{\Omega}\right)_{i j}\right]_{2} \\
& \left(g_{i j}\right)_{1}=-\int_{0}^{1} \phi_{i} \varphi_{j} d \bar{z} \\
& \left(g_{i j}\right)_{2}=\int_{0}^{1} \varphi_{i} \phi_{j} d \bar{z} \\
& {\left[\left(k_{e}\right)_{i j}\right]_{1}=\int_{0}^{1} \phi_{i}^{\prime \prime} \phi_{j}^{\prime \prime} d \bar{z}} \\
& {\left[\left(k_{e}\right)_{i j}\right]_{2}=\int_{0}^{1} \varphi_{i}^{\prime \prime} \varphi_{j}^{\prime \prime} d \bar{z}} \\
& {\left[\left(k_{s 1}\right)_{i j}\right]_{1}=\bar{k}_{x 1}\left\{\phi_{i}\left(\bar{z}_{1}\right)\right\}\left\{\phi_{j}\left(\bar{z}_{1}\right)\right\}^{T}} \\
& {\left[\left(k_{s 1}\right)_{i j}\right]_{2}=\bar{k}_{y 1}\left\{\varphi_{i}\left(\bar{z}_{1}\right)\right\}\left\{\varphi_{j}\left(\bar{z}_{1}\right)\right\}^{T}} \\
& {\left[\left(k_{s 2}\right)_{i j}\right]_{1}=\bar{k}_{x 2}\left\{\phi_{i}\left(\bar{z}_{2}\right)\right\}\left\{\phi_{j}\left(\bar{z}_{2}\right)\right\}^{T}} \\
& {\left[\left(k_{s 2}\right)_{i j}\right]_{2}=\bar{k}_{y 2}\left\{\varphi_{i}\left(\bar{z}_{2}\right)\right\}\left\{\varphi_{j}\left(\bar{z}_{2}\right)\right\}^{T}}
\end{aligned}
$$

For the sake of convenience, Eq. (14) can be rewritten as,

$$
[M]\{\ddot{X}\}+\gamma[G]\{\dot{X}\}+\gamma^{2}[K]\{X\}=0
$$

where

$$
[M]=\left[\begin{array}{cc}
{[M]_{1}} & 0 \\
0 & {[M]_{2}}
\end{array}\right]
$$

$$
\begin{aligned}
{[G] } & =2 \bar{\Omega}\left[\begin{array}{cc}
0 & {[G]_{1}} \\
{[G]_{2}} & 0
\end{array}\right] \\
{[K] } & =\left[\begin{array}{cc}
{\left[K_{e}\right]_{1}} & 0 \\
0 & {\left[K_{e}\right]_{2}}
\end{array}\right]+\bar{\Omega}^{2}\left[\begin{array}{cc}
{\left[K_{\Omega}\right]_{1}} & 0 \\
0 & {\left[K_{\Omega}\right]_{2}}
\end{array}\right] \\
& +\left[\begin{array}{cc}
{\left[K_{s 1}\right]_{1}} & 0 \\
0 & {\left[K_{s 1}\right]_{2}}
\end{array}\right]+\left[\begin{array}{cc}
{\left[K_{s 2}\right]_{1}} & 0 \\
0 & {\left[K_{s 2}\right]_{2}}
\end{array}\right]
\end{aligned}
$$

A space vector is introduced in Eq. (25) to solve the eigenvalue problem for the system.

$\{V\}=\left\{\begin{array}{l}\dot{X} \\ X\end{array}\right\}$.

Substituting Eq. (29) into Eq. (25), the equation can be rearranged as;

$\left[\begin{array}{cc}{[M]} & 0 \\ 0 & \gamma^{2}[K]\end{array}\right]\{\dot{V}\}+\left[\begin{array}{cc}\gamma[G] & \gamma^{2}[\mathrm{~K}] \\ -\gamma^{2}[\mathrm{~K}] & 0\end{array}\right]\{V\}=0$

The non-dimensional frequency $\bar{\omega}_{n}$ in Eq. (30), i.e., the natural frequency of the spindle system, is defined as:

$\bar{\omega}_{n}=\omega_{n} / \sqrt{\frac{E I}{\rho A L^{4}}}$ for $n=1,2, \ldots .$.

In industry, ball bearings are frequently used to support rotating spindles in rotating machinery. Recently, magnetic bearings have been employed increasingly to support spindles because they must rotate at higher speeds. Few investigations focused on the dynamic responses of defective spindle systems with magnetic bearings. Therefore, this investigation addresses the dynamic response of a cracked spindle supported by magnetic bearings.

\section{Crack Effect}

Considering a crack located at $\bar{z}=\bar{z} *$ on this spindle, the strain energy of the defective spindle will include the released energy caused by the crack. Fig. (2) shows the geometry of a cracked spindle. The released energy caused by a crack, as noted in [26], with a depth of $a$ may be expressed as:

$U^{c}=\int_{-b}^{b} \frac{\left(1-\mu^{2}\right)}{E} K_{I}^{2}(\xi) d \xi$

where $b=\sqrt{R^{2}-(R-a)^{2}}$

and $\mu$ is the Poisson's ratio of the spindle, $K_{I}$ is the stress intensity factor under a mode I load and $R$ is the radius of the spindle. In this case, the stress intensity factors $K_{I}$ can be approximated as

$$
K_{I}(\xi)=\frac{4 M_{b}}{\pi R^{4}} \sqrt{R^{2}-\xi^{2}} \sqrt{\pi \alpha} F_{2}(\alpha / h)
$$

where, $M_{b}$ is the bending moment, and

$$
h=2 \sqrt{R^{2}-\xi^{2}}
$$




$$
\begin{aligned}
& \alpha=a+\sqrt{R^{2}-\xi^{2}}-R \\
& F_{2}(\alpha / h)=\sqrt{\frac{2 h}{\pi \alpha} \tan \left(\frac{\pi \alpha}{2 h}\right)} \frac{0.923+0.199\left[1-\sin \left(\frac{\pi \alpha}{2 h}\right)\right]^{4}}{\cos \left(\frac{\pi \alpha}{2 h}\right)}
\end{aligned}
$$

The notations $a$ and $R$ are the maximum crack depth and radius of the spindle, respectively. Based on the investigations in [26, 27], alterations of the elastic deformation energy caused by lateral bending moments are the only important changes in the case of slender beams with a crack. The released energy of the crack with respect to $\xi$ due to the bending moment is obtained as:

$$
\begin{gathered}
U_{\xi}^{c}=E\left(1-\mu^{2}\right) \pi \int_{0}^{L} \int_{0}^{a} \int_{0}^{b}\left[\frac{\partial^{2} v}{\partial z^{2}} \delta\left(z-z^{*}\right)\right]^{2} \\
\left(R^{2}-\xi^{2}\right) \alpha F_{2}^{2}(\alpha / h) d \xi d \alpha d z
\end{gathered}
$$

Similarly, the released energy of the crack with respect to $\eta$ is derived as follows,

$$
\begin{aligned}
U_{\eta}^{c}= & E\left(1-\mu^{2}\right) \pi \int_{0}^{L} \int_{0}^{a} \int_{-b}^{b}\left[\frac{\partial^{2} u}{\partial z^{2}} \delta\left(z-z^{*}\right)\right]^{2} \\
& \xi^{2} \alpha F_{1}^{2}(\alpha / h) d \xi d \alpha d z
\end{aligned}
$$

where

$$
\begin{aligned}
F_{1}(\alpha / h)= & \frac{\sqrt{\frac{2 h}{\pi \alpha} \tan \left(\frac{\pi \alpha}{2 h}\right)}}{\cos \left(\frac{\pi \alpha}{2 h}\right)}
\end{aligned}
$$

For simplification, the dimensionless equations are employed as:

$$
\begin{aligned}
& U_{\eta}^{c}=\frac{4 R}{L}\left(1-\mu^{2}\right) \pi \int_{0}^{1}\left[\frac{\partial^{2} \bar{u}}{\partial \bar{z}^{2}} \delta\left(\bar{z}-\bar{z}^{*}\right)\right]^{2} Q_{1}\left(\frac{\xi}{R}, \frac{\alpha}{R}\right) d \bar{z} \\
& U_{\xi}^{c}=\frac{4 R}{L}\left(1-\mu^{2}\right) \pi \int_{0}^{1}\left[\frac{\partial^{2} \bar{v}}{\partial \bar{z}^{2}} \delta\left(\bar{z}-\bar{z}^{*}\right)\right]^{2} Q_{2}\left(\frac{\xi}{R}, \frac{\alpha}{R}\right) d \bar{z}
\end{aligned}
$$

where

$$
\begin{aligned}
& Q_{1}\left(\frac{\xi}{R}, \frac{\alpha}{R}\right)=\int_{0}^{a / R} \int_{0}^{b / R} \frac{\xi^{2}}{R^{2}} \frac{\alpha}{R} F_{1}^{2}(\alpha / h) d \frac{\xi}{R} d \frac{\alpha}{R} \\
& Q_{2}\left(\frac{\xi}{R}, \frac{\alpha}{R}\right)=\int_{0}^{a / R} \int_{-b / R}^{b / R}\left(1-\frac{\xi^{2}}{R^{2}}\right) \frac{\alpha}{R} F_{2}^{2}(\alpha / h) d \frac{\xi}{R} d \frac{\alpha}{R}
\end{aligned}
$$

The bearing-spindle with a crack can be obtained as:

$$
\begin{aligned}
& \ddot{\bar{u}}-2 \sqrt{\frac{E I}{\rho A L^{4}}} \bar{\Omega} \dot{\bar{v}}+\frac{E I}{\rho A L^{4}}\left\{-\bar{\Omega}^{2} \bar{u}+\left(\bar{u}^{\prime \prime}\right)^{\prime \prime}\right. \\
& -\frac{8 R}{L}\left(1-\mu^{2}\right) Q_{1}\left(\frac{\xi}{R}, \frac{\alpha}{R}\right)\left[\bar{u}^{\prime \prime} \delta\left(\bar{z}-\bar{z}^{*}\right)\right]^{\prime \prime} \\
& \left.+\bar{k}_{x 1} \bar{u} \delta\left(\bar{z}-\bar{z}_{1}\right)+\bar{k}_{x 2} \bar{u} \delta\left(\bar{z}-\bar{z}_{2}\right)\right\}=0 \\
& \ddot{\bar{v}}+2 \sqrt{\frac{E I}{\rho A L^{4}}} \bar{\Omega} \dot{\bar{u}}+\frac{E I}{\rho A L^{4}}\left\{-\bar{\Omega}^{2} \bar{v}+\left(\bar{v}^{\prime \prime}\right)^{\prime \prime}\right. \\
& -\frac{8 R}{L}\left(1-\mu^{2}\right) Q_{2}\left(\frac{\xi}{R}, \frac{\alpha}{R}\right)\left[\bar{v}^{\prime \prime} \delta\left(\bar{z}-\bar{z}^{*}\right)\right]^{\prime \prime} \\
& \left.+\bar{k}_{y 1} \bar{v} \delta\left(\bar{z}-\bar{z}_{1}\right)+\bar{k}_{y 2} \bar{v} \delta\left(\bar{z}-\bar{z}_{2}\right)\right\}=0
\end{aligned}
$$

Similarly, the equations of motion for the defective spindle, i.e. Eq. 13, can be rearranged in matrix form using Galerkin's method as follows:

$$
\begin{aligned}
& {\left[\begin{array}{cc}
{[M]_{1}} & 0 \\
0 & {[M]_{2}}
\end{array}\right]\left\{\begin{array}{l}
\ddot{p}(t) \\
\ddot{q}(t)
\end{array}\right\}+2 \bar{\Omega} \gamma\left[\begin{array}{cc}
0 & {[G]_{l}} \\
{[G]_{2}} & 0
\end{array}\right]\left\{\begin{array}{l}
\dot{p}(t) \\
\dot{q}(t)
\end{array}\right\}} \\
& +\gamma^{2}\left[\begin{array}{cc}
{\left[K_{e}\right]_{1}} & 0 \\
0 & {\left[K_{e}\right]_{2}}
\end{array}\right]\left\{\begin{array}{l}
p(t) \\
q(t)
\end{array}\right\}+\bar{\Omega}^{2} \gamma^{2}\left[\begin{array}{cc}
{\left[K_{\Omega}\right]_{1}} & 0 \\
0 & {\left[K_{\Omega}\right]_{2}}
\end{array}\right] \\
& \left\{\begin{array}{l}
p(t) \\
q(t)
\end{array}\right\}-\gamma^{2}\left[\begin{array}{cc}
{\left[K_{c}\right]_{1}} & 0 \\
0 & {\left[K_{c}\right]_{2}}
\end{array}\right]\left\{\begin{array}{l}
p(t) \\
q(t)
\end{array}\right\}+\gamma^{2}\left[\begin{array}{cc}
{\left[K_{s 1}\right]_{1}} & 0 \\
0 & {\left[K_{s 1}\right]_{2}}
\end{array}\right] \\
& \left\{\begin{array}{l}
p(t) \\
q(t)
\end{array}\right\}+\gamma^{2}\left[\begin{array}{cc}
{\left[K_{s 2}\right]_{l}} & 0 \\
0 & {\left[K_{s 2}\right]_{2}}
\end{array}\right]\left\{\begin{array}{l}
p(t) \\
q(t)
\end{array}\right\}=0
\end{aligned}
$$

where

$$
\begin{aligned}
& {\left[\left(k_{c}\right)_{i j}\right]_{1}=\frac{8 R\left(1-\mu^{2}\right)}{L} Q_{1}\left(\frac{\xi}{R}, \frac{\alpha}{R}\right)\left[\varphi_{i}^{\prime \prime}(\bar{z}) \varphi_{j}^{\prime \prime}(\bar{z})\right]_{\bar{z}=\bar{z}^{*}}} \\
& {\left[\left(k_{c}\right)_{i j}\right]_{2}=\frac{8 R\left(1-\mu^{2}\right)}{L} Q_{2}\left(\frac{\xi}{R}, \frac{\alpha}{R}\right)\left[\varphi_{i}^{\prime \prime}(\bar{z}) \varphi_{j}^{\prime \prime}(\bar{z})\right]_{\bar{z}=\bar{z}^{*}}}
\end{aligned}
$$

\section{Supported by Magnetic Bearing}

Few investigations on radial magnetic bearings were found, so these bearings were selected for this article. The rotor is kept in the desired position by a magnetic bearing stator using a magnetic field induced by permanent magnets. According to [21], the bearing force $F_{r}$ is derived as follows,

$$
F_{r}=\frac{B_{r 1} B_{r 2}}{4 \pi \mu_{0}} S
$$

Where $B_{r l}$ : remanence of the external magnetic loop for the magnetic bearing; $B_{r 2}$ : remanence of the internal magnetic loop for the magnetic bearing; $\mu_{0}$ : permanence in vacuum and,

$$
\begin{aligned}
S= & \left(S_{23}+S_{14}-S_{13}-S_{24}\right) \\
R x_{1} & =\left(x_{1}+x_{0}-x\right)^{2}+\left(e+R_{3} \cos \alpha-R_{2} \cos \beta\right)^{2} \\
& +\left(R_{3} \sin \alpha-R_{2} \sin \beta\right)^{2}
\end{aligned}
$$




$$
\begin{aligned}
& R x_{2}=\left(x_{1}+x_{0}-x\right)^{2}+\left(e+R_{3} \cos \alpha-R_{1} \cos \beta\right)^{2} \\
& +\left(R_{3} \sin \alpha-R_{1} \sin \beta\right)^{2} \\
& R x_{3}=\left(x_{1}+x_{0}-x\right)^{2}+\left(e+R_{4} \cos \alpha-R_{1} \cos \beta\right)^{2} \\
& +\left(R_{4} \sin \alpha-R_{1} \sin \beta\right)^{2} \\
& R x_{4}=\left(x_{1}+x_{0}-x\right)^{2}+\left(e+R_{4} \cos \alpha-R_{2} \cos \beta\right)^{2} \\
& +\left(R_{4} \sin \alpha-R_{2} \sin \beta\right)^{2} \\
& S_{23}=\int_{0}^{2 \pi} \int_{0}^{2 \pi} \int_{0}^{l_{m}} \int_{0}^{l_{m}} \\
& \frac{R_{2} R_{3}\left(e+R_{3} \cos \alpha-R_{2} \cos \beta\right) d \alpha d \beta d x d x_{1}}{R x_{1}^{3 / 2}} \\
& S_{13}=\int_{0}^{2 \pi} \int_{0}^{2 \pi} \int_{0}^{l_{m}} \int_{0}^{l_{m}} \\
& \frac{R_{1} R_{3}\left(e+R_{3} \cos \alpha-R_{1} \cos \beta\right) d \alpha d \beta d x d x_{1}}{R x_{2}^{3 / 2}} \\
& S_{14}=\int_{0}^{2 \pi} \int_{0}^{2 \pi} \int_{0}^{l_{m}} \int_{0}^{l_{m}} \\
& \frac{R_{1} R_{4}\left(e+R_{4} \cos \alpha-R_{1} \cos \beta\right) d \alpha d \beta d x d x_{1}}{R x_{3}^{3 / 2}} \\
& S_{24}=\int_{0}^{2 \pi} \int_{0}^{2 \pi} \int_{0}^{l_{m}} \int_{0}^{l_{m}} \\
& \frac{R_{2} R_{4}\left(e+R_{4} \cos \alpha-R_{2} \cos \beta\right) d \alpha d \beta d x d x_{1}}{R x_{4}^{3 / 2}}
\end{aligned}
$$

where $R_{l}$ : external radius of the external magnetic loop $R+2 h_{g}+L_{m g}$

$R_{2}$ : internal radius of the external magnetic loop $R+h_{g}+L_{m g}$

$R_{3}$ : external radius of the internal magnetic loop $R+h_{g}$

$R_{4}$ : internal radius of the internal magnetic loop $R$

$l_{m}:$ length of the magnetic loop

$L_{m g}$ : clearance between the internal and external magnetic loops

$h_{g}$ : the thickness of the magnetic loop

$e:$ is eccentric of the magnetic bearing

Consequently, the stiffness of a radial magnetic bearing can be derived as follows:

$k_{m}=\frac{F_{r}}{e}=\frac{B_{r 1} B_{r 2}}{4 \pi \mu_{0}} \frac{S}{e}$

\section{ANALYSIS AND DISCUSSION}

In ultra-high-speed machining, using magnetic bearings to support the spindle is necessary [28]. The dynamic properties of a multi-mode spindle with bearings of the size actually used in engineering applications are addressed and a magnetic bearing is considered in this work. The dimensions $R=0.02 \mathrm{~m}$ and $L=0.2 \mathrm{~m}$ of a rotating spindle are assumed. The bearings positions are assumed to be $\bar{z}_{1}=0$ and $\bar{z}_{2}=1$.

A spindle system braced by a magnetic bearing is important in engineering applications, especially for highspeed rotational machinery. For the above-mentioned spindle dimensions, the important magnetic bearing parameters were selected as follows. $\mathrm{Nd}-\mathrm{Fe}-\mathrm{B}$ material was employed to model the elements of a permanent magnet in the radial magnetic bearings. For this material, the remanence $B_{r 1}=B_{r 2}$ $=1.13 \mathrm{wb} / \mathrm{m}^{2}$ can be shown. Corresponding to the spindle imension, the length of the magnetic $l_{m}=20 \mathrm{~mm}$ and the clearance $L_{m g}=0.001 \mathrm{~m}$ were assumed.

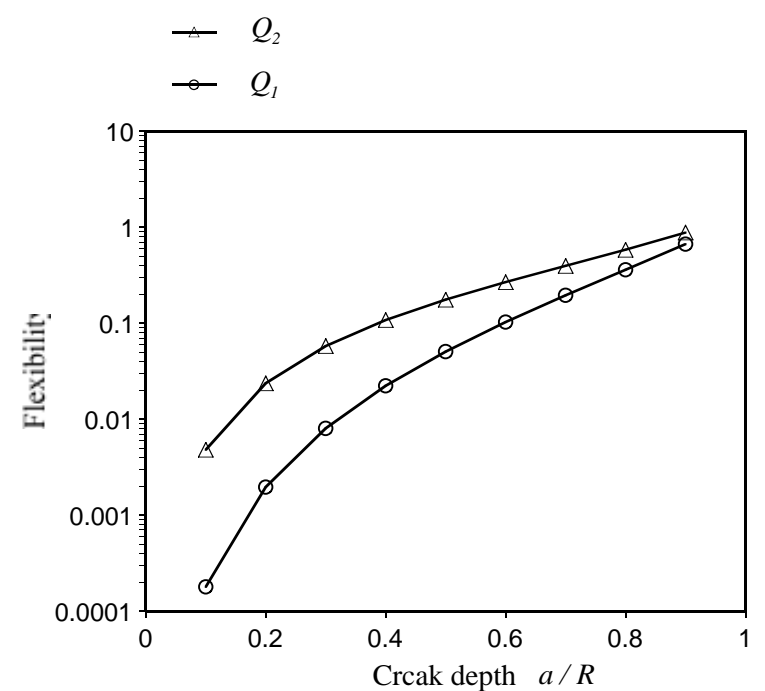

Fig. (3). The variations in the crack flexibility with the crack depth ratio.

The variation in the crack flexibility with the crack depth ratio is plotted in Fig. (3). The numerical analysis reveals that the crack flexibility increases as the crack depth is increased. From the results, the crack depth markedly affects the shaft stiffness. As a whole, these results and those from previous investigation [29] are identical. Fig. (4) presents the natural frequencies of a spindle bearing system with and without cracks. The logarithmic scale was employed to study higher modes in this figure. At lower modes, the natural frequencies of the spindle bearing system change slightly regardless of whether there is a crack or not in the system. However, at higher modes, the natural frequencies of a spindle bearing system decrease when there is a crack in this spindle system. With magnetic bearings, the crack effect on the dynamics of a spindle system has more influence at the higher modes than at the lower modes. The effect of the crack depth on the natural frequencies is considered in Fig. (5). In this figure, the lower and higher mode natural frequencies, the $1^{\text {st }}$ and $5^{\text {th }}$ modes, are studied together. Both the $1^{\text {st }}$ and $5^{\text {th }}$ natural frequencies decrease with increasing crack depth. If the crack depth were $\bar{\gamma} \leq 0.1$, the crack size would have little influence on the natural frequencies of a rotating blade system. However, the natural frequencies are depressed significantly when the crack size is larger than 0.1 . 


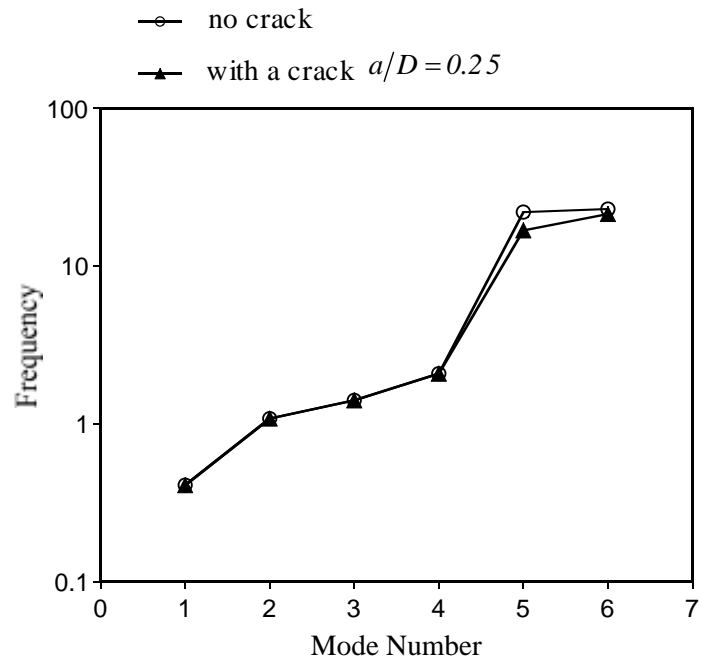

Fig. (4). The natural frequencies of a magnetic-bearing spindle with and without a crack, $\left(\bar{\Omega}=0.5, a / D=0.25, \overline{\mathrm{z}}^{*}=0.5\right)$.

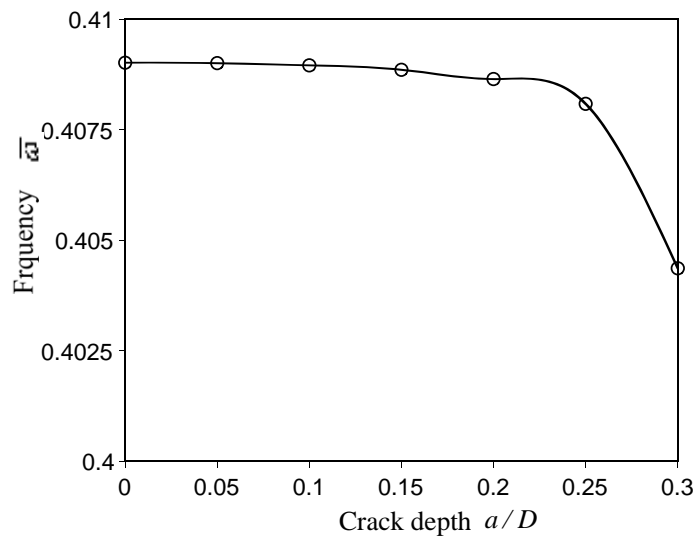

(a) the 1st mode

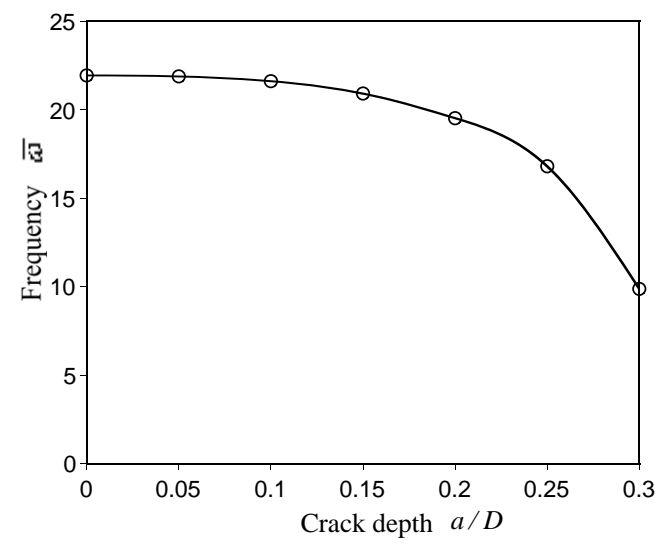

(b) the 5th mode

Fig. (5). The natural frequencies of a magnetic-bearing spindle with different crack depths, $\left(\bar{\Omega}=0.5, \overline{\mathrm{z}}^{*}=0.5\right)$.

Crack location dramatically changes the dynamics of a spindle with magnetic bearings. Fig. (6) shows the variation in the natural frequencies of a spindle with different crack locations. As mentioned above, only the $1^{\text {st }}$ and $5^{\text {th }}$ natural frequencies were examined. When the crack is located at both ends, the natural frequencies are almost the same as a system without a crack. The value of the natural frequencies of the system is the lowest when the crack is located at the middle of the spindle. The phenomena illustrated in Fig. (6a) and (6b) are similar. The effect of rotation speed on the dynamics of a cracked spindle with magnetic bearings is plotted in Fig. (7). Double roots for the natural frequencies of a cracked spindle with magnetic bearings are observed only if this system has no rotation speed. With rotation speed, the natural frequencies of this system are divided into two parts, the forward and backward frequencies. Only the $1^{\text {st }}$ and $2^{\text {nd }}$ natural frequencies are shown in this figure. The $1^{\text {st }}$ natural frequency of a cracked spindle with magnetic bearings increases as the rotational speed increases. However, it was found that if the rotational speed increases, the $2^{\text {nd }}$ natural frequency decreases.

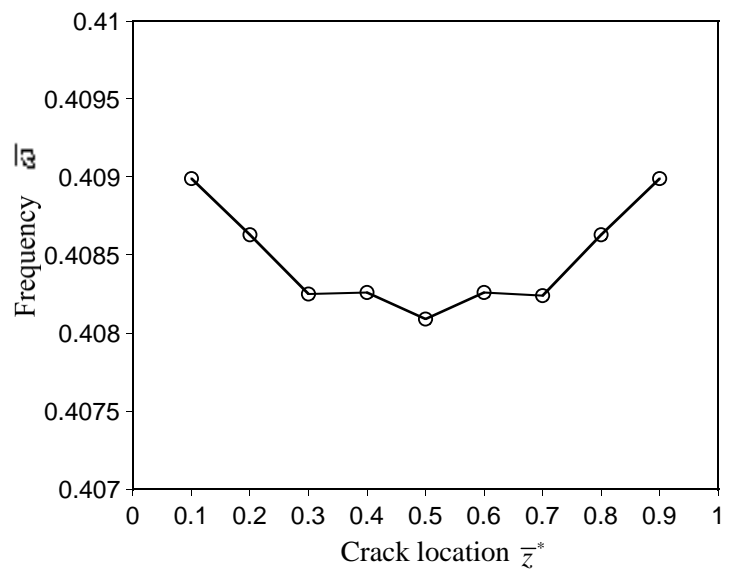

(a) the 1 st mode

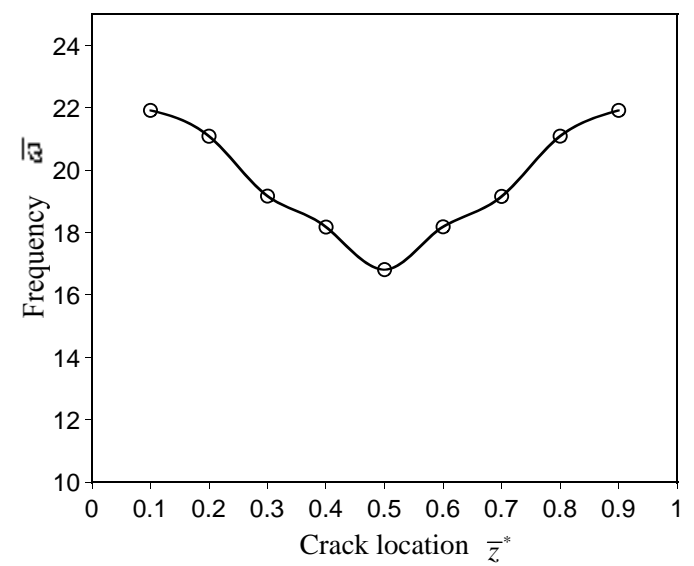

(b) the 5th mode

Fig. (6). The natural frequencies of a magnetic-bearing spindle with different crack locations, $(\bar{\Omega}=0.5, a / D=0.25)$.

For radial magnetic bearings, the length of the bearings remarkably alters the system stiffness. Fig. (8) illustrates the variations in natural frequencies for a cracked spindle with different magnetic bearing lengths. The results indicate that the natural frequencies of a magnetic-bearing spindle increase as the magnetic bearing length increases. Finally, the frequency responses of a spindle system with and without cracks are illustrated in Fig. (9). Both the lower and higher frequency domains were examined. In the lower frequency domain, the figure shows that the frequency response of a bearing-spindle system without a crack is almost the same as one with a crack. The peak frequency response values for a spindle with magnetic bearings are depressed in the higher frequency 
domain if there is a crack in the spindle. As above, the effect of a crack may significantly influence the dynamics of a spindle system with magnetic bearings at higher modes.

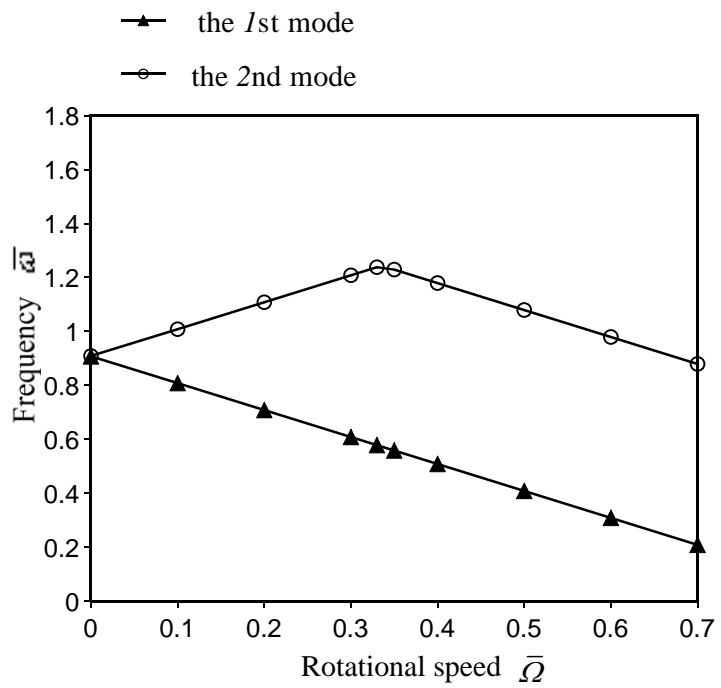

Fig. (7). The natural frequencies of a magnetic-bearing spindle with different rotational speeds, $\left(\bar{z}^{*}=0.5, a / D=0.25\right)$.

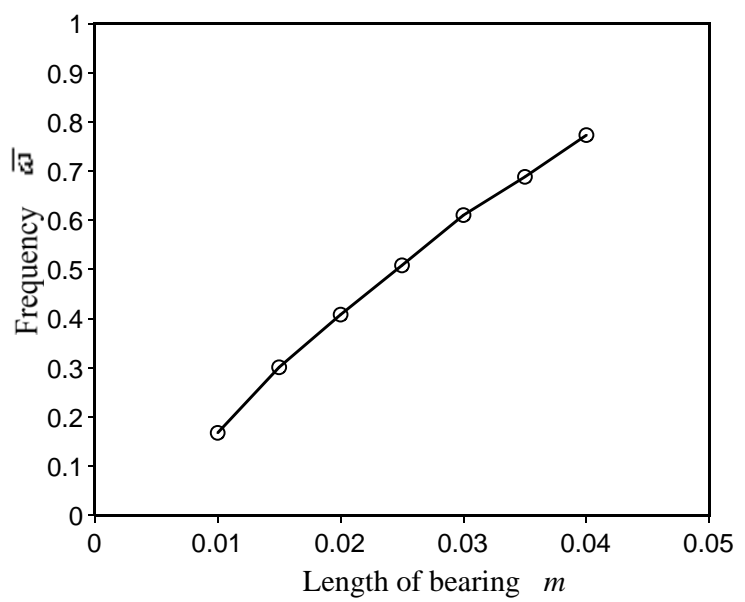

Fig. (8). The natural frequencies of a rotating cracked spindle with different lengths of magnetic bearing, $\left(\bar{z}^{*}=0.5, a / D=0.25\right)$.

\section{CONCLUSIONS}

The effect of cracks on the dynamics of a spindle supported by magnetic bearings was studied. The most significant observations in this study are summarized as follows:

1. With magnetic bearings, the natural frequencies of a spindle system decrease as the depth of the crack increases.

2. At higher modes, a crack will markedly affect the dynamics of a spindle with magnetic bearings. However, at lower modes, the natural frequencies of the spindle bearing system change just slightly no matter whether there is a crack or not.

3. The rotational speed and magnetic bearing length will significantly influence the dynamics of a spindle with magnetic bearings.

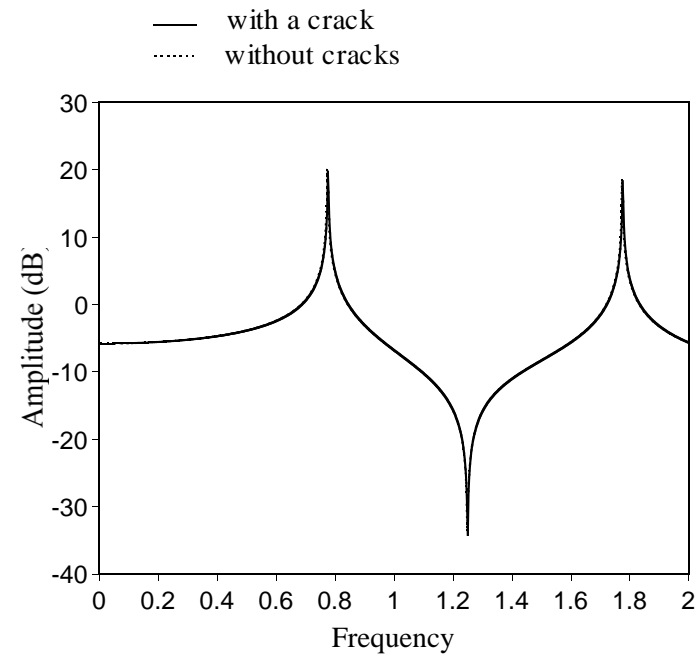

(a) a lower frequency domain

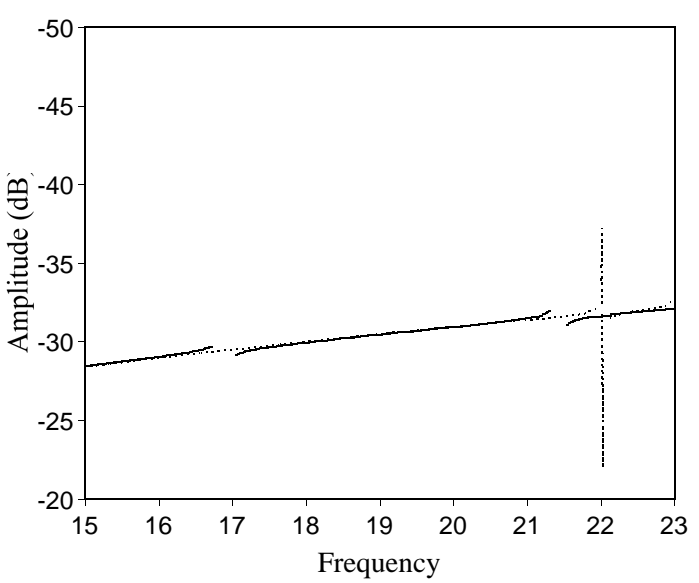

(b) a higher frequency domain

Fig. (9). The frequency response of a rotating spindle with and without a crack, ( $\bar{\Omega}=0.5, a / D=0.25, \overline{\mathrm{z}}^{*}=0.5$ )

4. The crack will dramatically affect the dynamic characteristics of a spindle with magnetic bearings if the crack is located at the middle of the spindle.

\section{REFERENCES}

[1] S. C. Huang, Y. M. Huang and S. M.Shieh, "Vibration and Stability of a Rotating Shaft Containing a Transverse Crack", Journal of Sound and Vibration, vol.162, pp. 387-401, 1993.

[2] S. K. Bhaumik, R. Rangaraju, M. A. Venkataswamy, T. A. Bhaskaran and M. A. Parameswara, "Fatigue fracture of crankshaft of an aircraft engine", Engineering Failure Analysis, vol. 9(3), pp. 255-263, 2002.

[3] P. F. Rizos, N. Aspragathos, A. D. Dimarogonas, "Dimarogonas Identification of Crack Location and Magnitude in a Cantilever Beam from the Vibration Mode," Journal of Sound and Vibration, vol. 138, pp. 381-388, 1990.

[4] D. Broek, "Elementary Engineering Fracture mechanics", Martinus Nijhoff Publishers, 1986.

[5] H. Tada, P. Paris and G. Irwin, "The Stress Analysis of Crack Handbook", Hellertown, Pennsylvania: Del Research Corporation, 1973.

[6] B. Grabowski, "The Vibrational Behavior of a Turbine Rotor Containing a Transverse Crack", ASME, Journal of Mechanic Design, vol. 102, pp. 140-146, 1980.

[7] A. S. Sekhar, "Effects of cracks on rotor system instability", Mechanism and Machine Theory, vol. 35(12), pp. 1657-1674, 2000

[8] N. Bachschmid, P. Pennacchi, E. Tanzi and A. Vania, "Identification of transverse crack position and depth in rotor systems", Meccanica, vol. 6 , pp. 563-582, 2000. 
[9] P. N. Savedra and L .A. Cuitino, "Vibration analysis of rotor for crack identification", Journal of Vibration and Control, vol. 8(1), pp.51-67, 2002.

[10] M. J. Goodwin, "Dynamics of Rotor-Bearing System", Unwin Hyman, London, 1989.

[11] J. A. Brandon and K. J. H. Al-Shareef, "On The Applicability of Modal and Response Representations in The Dynamic Analysis of Machine Tool Spindle Bearing Systems", IMechE, Journal of Engineering Manufacture, vol. 205, pp. 139-145, 1991.

[12] B.R. Jorgensen and Y. C. Shin, "Dynamics of Spindle-Bearing Systems at High Speeds Including Cutting Load Effects", ASME, Journal of manufacturing Science and Engineering, vol. 120, pp. 387-394, 1998.

[13] W. R. Wang and C. N. Chang, "Dynamic Analysis and Design of a Machine Tool Spindle-Bearing System", ASME, Journal of Vibration and Acoustics, vol. 116, pp. 280-285, 1994

[14] R.G. Parker and C. j. Mote, "Vibration and Coupling Phenomena in Asymmetric Disk-Spindle Systems", ASME, Journal of Applied Mechanics, vol. 63, pp. 953-961, 1996.

[15] I.Y. Shen, "Closed-Form Forced Response of a Damped, Rotating, Multiple Disks/Spindle System", ASME, Journal of Applied Mechanics, vol. 64, pp. 343-352, 1997.

[16] F.T. Barwell, Bearing System, Principles and Practice, Oxford University Press, New York, 1979.

[17] M. Chinta and A. B. Palazzolo, "Stability and Bifurcation of Rotor Motion in a Magnetic Bearing", Journal of sound and vibration, vol. 214(5), pp. 793-803, 1998

[18] C. Delprete, G. Genta and A. Repaci, "Numerical Simulation of the Dynamic Behavior of Rotors on Active Magnetic Bearings", In: Proceedings of the $7^{\text {th }}$ International Symposium on Transport Phenomena and Dynamics of Rotating Machinery, Honolulu, Hawaii, USA, 1998.

[19] M. Komori and T. Hamasaki, "Improvement and Evaluation of Bearing Stiffness in High Tc Superconducting Magnetic Bearing", IEEE Transactions on Applied Superconductivity, vol. 11(1), pp. 1677-1680, 2001.
[20] H. Chang and S. C. Chung, "Integrated Design of Radial Active Magnetic Bearing Systems Using Genetic Algorithms", Mechatronics, vol. 12(1), pp.19-36, 2002.

[21] Q. Tan, M. Liu and H. Meng, "Study on Bearing Capacity and Stiffness of Radial Magnetic Bearing", Journal of Tribology (in China), vol. 14(4), pp. 337-344, 1994.

[22] Y. He, D. Guo and F. Chu, "Using genetic algorithms to detect and configure shaft crack for rotor-bearing system", Computer Methods in Applied Mechanics and Engineering, vol. 190(45), pp. 5895-5906, 2001

[23] M. A. Mohiuddin and Y. A. Khulief, "Dynamic response analysis of rotor-bearing systems with cracked shaft", ASME, Journal of Mechanical Design, vol. 124(4), pp. 690-696, 2002.

[24] S. Prabhakar and A. S. Sekhar and A R. Mohanty, "Detection and monitoring of cracks in a rotor-bearing system using wavelet transforms", Mechanical Systems and Signal Processing, vol. 15(2), pp. 447-450, 2001.

[25] B. W. Huang and H. K. Kung, "A Variation of Instability in a Rotating Spindle System with Various Bearings", International Journal of Mechanical Science, vol. 45(1), pp. 57-72, 2003.

[26] A. D. Dimarogonas and S. A. Paipetis, "Analytical Methods in Rotor Dynamics", Applied Science Publishers, New York, 1983.

[27] M. Krawczuk and W. M. Ostachowicz, "Transverse Natural Vibrations of a Cracked Beam Loaded with a Constant Axial Force", ASME, Journal of Vibration and Acoustics, vol. 115, pp. 524-528, 1993.

[28] S. Herranz, F. J. Campa, L N López de Lacalle, et al., "The milling of airframe components with low rigidity: a general approach for the avoidance of static and dynamic problems", Procc. Int. Mechanical Inst. Part B Journal of Engineering Manufacture, vol. 219(B11), pp. 789-801, 2005

[29] M. C. Wu and S. C. Huang, "Vibration and Crack Detection of a Rotor with Speed-Dependent Bearings", International Journal of Mechanical Science, vol. 40(6), pp. 545-555, 1998.

(C) Kung and Huang; Licensee Bentham Open.

This is an open access article distributed under the terms of the Creative Commons Attribution License (http://creativecommons.org/licenses/by/2.5/), which permits unrestrictive use, distribution, and reproduction in any medium, provided the original work is properly cited. 